\title{
Formulation and Evaluation of Poly Herbal Liqui-Solid Compact for its Anti-Inflammatory Effect
}

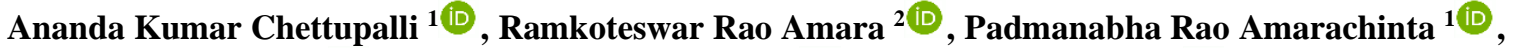 \\ Ram Mohan Manda ${ }^{1}$, Baba Shankar Rao Garige ${ }^{1}$ (D), Vinod Kumar Yata ${ }^{3, *}$ (D) \\ 1 Center for Nanomedicine, Department of Pharmaceutics, School of Pharmacy, Anurag University, Hyderabad, 501301, \\ Telangana State, India \\ 2 Research Scholar, Shri. J. J.T.University, Jhunjhunu, Churu Rd, Vidyanagari, Churela, Rajasthan 333001, India \\ 3 Animal Biotechnology Centre, National Dairy Research Institute (NDRI), Karnal-132001, India \\ * Correspondence: vinodyata@gmail.com (V.K.Y.);
}

Scopus Author ID: 36553530200

Received: 2.04.2021; Revised: 10.06.2021; Accepted: 14.06.2021; Published: 13.08.2021

\begin{abstract}
Liquisolid approach is a potential method due to the ease in the production process, low cost, and manufacturing process because of their strong flow and compaction properties. The study's main goal is to create a liquisolid powder formulation from the polyherbal extract and evaluate its antiinflammatory activity. Hibiscus cannabinus, Murraya koenigii, and Tabernaemontana divaricate are used to formulating polyherbal Liquisolid powder formulation to assess their anti-inflammatory action. The formulation is tested for its stability studies and anti-inflammatory activity, both in-vitro and invivo. The polyherbal liquisolid powder formulation (F5) has a minimum strength of $1 \mathrm{~kg} / \mathrm{cm}^{2}$, while F2 \& F6 strength was $4 \mathrm{~kg} / \mathrm{cm}^{2}$; FTIR studies showed no interactions between drug and excipients. To confirm the liquisolid powder formulation, further evaluations on friability, hardness, disintegration time, dissolution rate, and Differential scanning calorimetry and X-ray powder diffraction analysis were determined. The polyherbal extract's anti-inflammatory activities were evaluated using the paw edema and cotton pellet method, and the results are found to exhibit its inhibitory activity. The polyherbal extract of Liquisolid powder formulation was evaluated, and it showed a promising inhibitory activity to overcome the inflammation in the test species. Hence it can be used as an alternative therapy for curing inflammation.
\end{abstract}

Keywords: Hibiscus cannabinus; Murraya koenigii; Tabernaemontana divaricate; polyherbal extracts; liquisolid powder formulation.

(C) 2021 by the authors. This article is an open-access article distributed under the terms and conditions of the Creative Commons Attribution (CC BY) license (https://creativecommons.org/licenses/by/4.0/).

\section{Introduction}

The peroral route is found to be the most suitable route of administration and possesses a cost-effective nature. The low solubility of drugs is absorbed slowly by the Gastrointestinal Tract (GIT) due to its passive absorption [1]. The liquisolid technology increased the dissolution rate, the flow rate of poorly soluble drugs by compressing solid substances using carrier and coating material [2].

Liquisolid systems contain a non-volatile liquid, water-miscible carrier, solid particles, and selected excipients to prepare any given polyherbal formulations. In a given porous carrier material, a liquid and drug suspension is acceptable for preparing formulation where a nonvolatile liquid vehicle is included [3]. When the liquid film is formed on the particle's surface, it gets adsorbed immediately due to its nature. This produces a dry, free flow and compressible 
powder. Besides the increase in drug release, the liquisolid approach is promising due to its ease in production, low costs, and strong flow properties $[4,5]$.

Hibiscus cannabinus $L$. is a quick groove, woody, and herbaceous annual Malvaceae family plant, commonly known as "Kenaf" in the western world. The plant has many conventional applications, including hepatoprotective [6], hematinic activity [7], lowering cholesterol [8], and antioxidant properties [9]. Commonly Murraya koenigii is known as 'curry patta' used in India and other tropical countries as a spice and condiment [10]. Traditionally, the plant is used as a stimulant for diarrhea therapy, dysentery, stomach ache, febrifugal, and analgesic activity. The herb is commonly distributed in Asia is Tabernaemontana divaricate L. and belongs to the Apocynaceae family. It is used to treat bacterial, fungal, parasitic, and inflammatory diseases in conventional medicine in many Asian countries [11, 12].

Nowadays, herbal medicine has become more critical because of its potential therapeutic effects with fewer adverse effects. Many plants have medicinal values with negligible adverse effects and should be researched extensively to determine their therapeutic effects and their molecular mechanism for safe use [13]. The selected plants used in the analysis are traditionally used for different therapeutic effects such as anti-inflammatory, antipyretic, and analgesic activity. Further, the plants' polyherbal extract was prepared and evaluated by formulating a Liquisolid Powder Formulation for determining their synergistic activity [14, $15]$.

\section{Materials and Methods}

\subsection{Plant material.}

The plant's materials chosen for the analysis are Hibiscus cannabinus, Murraya koenigii, Tabernaemontana divaricate. These plants' leaves were collected from Visakhapatnam, India, and were authenticated by Dr. M. Venkaiah, professor, Department of Botany, Andhra University, A.P, India.

\subsection{Chemicals and reagents.}

All the chemical and reagents used for the study are analytical reagents grade. methanol, carrageenan, indomethacin sodium, hydrochloric acid, phosphate buffer, span 20, span 80, propylene glycol, and other reagents were procured from Sun biotech, Hyderabad, Telangana.

\subsection{Preparation of the polyherbal extract.}

Hibiscus cannabinus (Hc), Murraya koenigii (Mk), Tabernaemontana divaricate $(\mathrm{Td})$, was collected and shaded under the sun for a week and powdered to 80\#, and macerated with methanol separately. The mixture is well blended and filtered with Whatman Filter Paper No.1 after a week. The filtrate obtained is subjected to vacuum filtration at $43^{\circ} \mathrm{C}$ for obtaining crude extracts [16].

\subsection{Polyherbal extracts phytochemical screening.}

Preliminary phytochemical screening was conducted with standard methods for determining the phytochemical components in the given extracts $[17,18]$. 


\subsection{Animals.}

The male Wistar rats weighing 150-200gm were used for the study with the approval from Institutional Animal and Ethical Committee, wide number I/IAEC/AGI/0102019 WR §̂or + . The animals were fed with standard rat pellets diet, water ad libitum, and were housed at RH 30-60\% with a temperature of $25 \pm 2{ }^{\circ} \mathrm{C}$.

\subsection{Acute oral toxicity studies.}

Acute oral toxicity tests for polyherbal extract have been carried out in compliance with OECD 425 guidelines. The limit test was a sequential test using up to 5 animals with a bodyweight of $2000 \mathrm{mg} / \mathrm{kg}$ body weight. The animals were monitored for toxicities, and signs of symptoms were studied for 48 hours $[19,20]$.

\subsection{Anti-inflammatory activity (in-vitro screening method).}

\subsubsection{Method of denaturation of protein.}

Polyherbal extracts at different concentrations were denatured by the protein denaturation process method. The reaction mixture $(0.5 \mathrm{~mL})$ consisted of $0.45 \mathrm{ml}$ of Bovine serum albumin (BSA) /and $0.05 \mathrm{ml}$ poly-herbal extract in various amounts. The samples were incubated for 30 minutes at $37^{\circ} \mathrm{C}$. After cooling the samples, the $2.5 \mathrm{ml}$ of phosphate buffer saline ( $\mathrm{pH}$ 6.3) has been taken into each test tube. The turbidity of the samples was monitored and recorded at $660 \mathrm{~nm}$ using a spectrophotometer. $0.05 \mathrm{ml}$ of sterile water was used in place of extracts which served as control. The inhibitory percentage was determined as per the following formula $[21,22]$.

$$
\text { Percent inhibition }=\frac{\text { AbsControl-Abstreated }}{\text { AbsControl }} \times 100
$$

The control was showing $100 \%$ denaturation of the protein. The findings were compared with treated samples of acetylsalicylic acid $(250 \mathrm{mg} / \mathrm{ml})$.

\subsection{Anti-inflammatory activity (in-vivo screening methods).}

\subsubsection{Carrageenan-induced paw edema test.}

The acute anti-inflammatory activity was evaluated by the rat-paw edema method (111). The test and standard drug formulations were administered orally for all the groups. After one hour of administration, carrageenan $(0.1 \mathrm{ml}$ of $1 \%$ Normal saline) was injected sub planter surface on each rat's left hind paw. Labeling was done on hind feet just at the tibiotarsal junction so that paw volume can be measured by dipping in the mercury column of the plethysmograph up to the mark. The paw volume was determined by using a plethysmometer. The paw volume was measured at $0 \mathrm{hrs}, 1 \mathrm{hrs}, 2 \mathrm{hrs}$, $3 \mathrm{hrs}$, and $4 \mathrm{hrs}$ of intervals, respectively. Edema volumes in control $(\mathrm{Vc})$ and test $(\mathrm{Vt})$ treatment groups were determined accordingly $[23,24]$. The percentage increase in paw volume was determined using the following formulae,

$$
\% \text { Inhibition }=\mathrm{Vc}-\mathrm{Vt} / \mathrm{Vc} \times 100
$$

where $\mathrm{Vc}=$ edema volume of control; $\mathrm{Vt}=$ edema volume of the test. 


\subsubsection{Cotton pellet granuloma test.}

The rats were divided into 4 groups of 6 animals each, and the back of the neck was shaved. Cotton pellets of $10 \mathrm{mg}$ each were sterilized for about 1 hour and inserted subcutaneously into the rats with light anesthesia on each side of the subcutaneous region. After cotton pellets had been inserted, all four groups formed were treated orally for 7 consecutive days. Indomethacin sodium was treated in the normal rats $(10 \mathrm{mg} / \mathrm{kg}$, body weight $)$. On the 8 th day, ether was used to sacrifice animals, and pellets were dissected and removed. The pellets were dried at $60^{\circ} \mathrm{C}$, and the weight was determined by drying. The difference between the initial and final weight was considered as the weight of the granulomatous tissue developed was measured $[25,26]$. The proportion of granulomatous tissue formation by inhibition was calculated according to the following formula

$$
\% \text { Inhibition }=[1-\mathrm{Wt} / \mathrm{Wc}] \times 100
$$

where granulation weight $(\mathrm{Wt})$ - in the treated group; Wc -in the control group.

\subsection{Statistical analysis.}

The data were expressed as MEAN \pm SEM. The data obtained were subjected to oneway variance analysis (ANOVA), followed by the non-test of Dennett.

Polyherbal extracts determination in various non-volatile solvents:

These have been carried out by preparing saturated herbal extract solutions in nonvolatile solvents and were analyzed spectrophotometrically [27]. Saturated solutions were developed by applying the excess drug to vehicles and shaking them under steady vibration. The solutions were subsequently filtered and spectrophotometrically analyzed.

\subsection{Load factor calculation.}

The amount of liquid retained by the carrier and coating materials in a liquisolid system is dependent on the ratio $(\mathrm{R})$, while preserving proper flow and compressive properties. The excipient ratio $\mathrm{R}(\mathrm{R}=\mathrm{Q} / \mathrm{q})$ of a powder is defined as the proportion of carrier $(\mathrm{Q})$ weights to cover material $(\mathrm{q})$ in the formulation. The preparation of a proper flow and compressibility of the liquisolid system will occur if the maximum amount of liquid retained from the carrier material is not exceeded. This characteristic liquid quantity is called the liquid load factor (Lf). The fluid load factor is defined as the liquid medication (W) and carrier powder (Q) weight ratio of the device, i.e., $\mathrm{Lf}=\mathrm{W} / \mathrm{Q}$ ). Propylene glycol (liquid drug without medication) is applied to the $10 \mathrm{~g}$ carrier material and blended for about a min to measure the loading factor [28]. The above process was repeated until a powder was obtained with an appropriate flow rate.

\subsection{Solubility studies.}

In each vehicle excess, the polyherbal extract was injected into the $2 \mathrm{ml}$ Clicklock microcentrifuge tubes (Tarsons Products Pvt. Ltd., Kolkata, India), containing $1.5 \%$ of the vehicle for solubility studies. The mixture was vortexed and held at $25^{\circ} \mathrm{C}$ for $48 \mathrm{~h}$ in an orbit shaking incubator to promote the solubilization process [29, 30] (Remi Elektrotechnik Ltd., CIS-2413L, Mumbai, India). The samples were centrifuged to extract the unresolved medication at $3000 \mathrm{rpm}$ for $15 \mathrm{~min}$. The supernatant was taken, and a UV spectrophotometer determined the drug concentration. 


\subsection{Preparation of liquisolid powder compacts.}

The weighted sum of the polyherbal extract was distributed over the measured number of non-volatile solvents called liquid vehicles. The mixing process was carried out in three phases as per Spireas et al. [31]. The first was the blend with liquid drug the weighted quantity of carrier material (Microcrystalline cellulose PH 102) to disperse the liquid drugs uniformly into the powder. The measured amount of coating material (AEROSIL® 200) was applied to the device in continuous mortar shredding. Finally, sodium starch glycolate was applied to the mixture mentioned earlier of super disintegrating agent for 10-20 min and produced the final liquisolid compact powder formulation compressed using a tabletop pilot scale 10 station rotary tablet (Rimek mini press-I, M/S Karnavati Engineering Ltd., Gujarat, India).

\subsection{Micromeritic properties of prepared liquisolid powder systems pre-compressed.}

To examine the Angle of repose $(\theta)$, a fixed funnel method was used. A weighed amount of polyherbal extract was transferred from each batch into a graduated cylinder to detect the bulk and tap density using a USP-I density tester (TD 1025, Lab India Instruments Mumbai, India). Triplicate studies were conducted. The selected parameters for the analysis of flow properties were calculated by the following equations.

$\begin{array}{ll}\text { Bulk Density }\left(\rho_{\mathrm{o}}\right) & =\text { Weight of the powder/volume occupied by sample }(\mathrm{ml}) \\ \text { Tapped Density }\left(\rho_{\mathrm{t}}\right) & =\text { Weight of the powder/tapped volume }\left(\mathrm{V}_{\mathrm{f}}\right) \\ \% \text { compressibility index } & =\left[\left(\rho_{\mathrm{t}}-\rho_{\mathrm{o}}\right) / \rho_{\mathrm{t}}\right] \times 100 \\ \text { Hausner's ratio } & =\rho_{\mathrm{t}} \rho_{\mathrm{o}} \\ \text { Angle of repose } & =\tan ^{-1}(\mathrm{~h} / \mathrm{r})\end{array}$

\subsection{Formulation of liquisolid power compacts polyherbal extracts.}

Plant leaf extracts of Hibiscus cannabinus, Murraya koenigii, Tabernaemontana divaricate were taken in the ratio of 1:1:1 and were well blended using a blender. The Polyherbal formulation is then moved to a sterile container and stored for further use. Liquisolid compacts were prepared using Tanscutol Hp, propylene glycol, tween 80, tween 20, methanol, and hydro-alcohol. Polyherbal extracts were formulated into liquisolid compacts using different quantities in six separate formulations (Table 6).

\subsection{Polyherbal formulation post-compression studies for evaluation.}

Further evaluation of PHF for thickness $(n=6)$, hardness $(n=20)$, friability $(n=20)$ and weight variation $(n=20)$ has been carried out as per Indian pharmacopeia. Polyherbal formulation content analysis in every batch was performed by taking 20 tablets in a mortar and pestle. The finely powdered sample was weighed and dissolved in $250 \mathrm{ml}$ of the volumetric flask containing $100 \mathrm{ml}$ of a solvent mixture of methanol and water in the ratio of 1:1. The flask was placed in an orbital shaker (Remi, Electrotechnik Ltd., Vasai, India). Temperature and rpm were set to $27^{\circ} \mathrm{C}$ and $150 \mathrm{rpm}$, respectively. Shaking persisted for 72 hours and was later filtered using $0.45 \mu \mathrm{m}$ Whatman filter paper. The small quantity of initial filtrate was discarded, and a sufficient volume of the filtrate was collected. The amount of the drug was measured in HPLC using sufficient diluted samples. Digital Vernier Callipers (CD-6" CSX, Mitutoyo Corp., Kawasaki, Japan) have been used to assess the polyherbal formulation 
thickness. Monsanto hardness tests (MHT-20, Kshitij International, and Ambala, India) were measured using the standard formula for the given polyherbal formulations. The friability of polyherbal formulation has been calculated by Roche friabilator (FT 1020, Lab India, and Mumbai, India). The disintegration time of the polyherbal formulation was calculated with the disintegration test apparatus (DT 1000, Lab India, and Mumbai, India). The weight variation studies were performed using an electronic balance as per USP method (ATX224, Shimadzu, Japan).

\subsection{Physico-chemical characterization.}

Fourier Transform Infrared Spectroscopy (FTIR): FTIR was conducted to understand the chemical interactions between drugs and excipients. FTIR spectra (Bruker, Alpha-T, Ettlingen, Germany) were obtained for all herbal extracts (Hibiscus Cannabinus, Murrayakoenigii Tabernaemontana. divaricata) and MCC PH 102, Aerosil@ 200, sodium starch glycolate, and optimized polyherbal liquisolid powder compacts. The samples were prepared by hydraulic pellet presses with a pressure of $10 \mathrm{t}$ using $\mathrm{KBr}$ discs. The samples were scanned between 4000 and $400 \mathrm{~cm}^{-1}$ when characteristic peaks were depicted with additional peaks indicating the absence of chemical interactions in the given formulations [32].

\subsection{Differential scanning calorimetry (DSC).}

DSC thermogram for pure herbal extracts, MCC PH 102, AEROSIL® 200, sodium starch glycolate, and optimized polyherbal powder compacts were analyzed using DSC (Model: SIIO-6300, Japan). The experimental samples of about $3 \mathrm{mg}$ were taken in an aluminum pan and crumpled with a crimper. The samples' thermal behavior was measured using nitrogen gas as blank in the temperature range of 0 to $30^{\circ} \mathrm{C}$ with a scanning rate of 10 ${ }^{\circ} \mathrm{C} / \mathrm{min}[33]$.

\subsection{8. $X$-ray diffraction $(X R D)$.}

The XRD patterns for polyherbal extracts and the optimized polyherbal liquisolid powder compacts were further characterized for their crystallinity. X-ray powder diffraction studies were done by XRD (Model: Stereo scans S120, Cambridge, UK). The samples are loaded onto the diffractometer, and then they were exposed to $\mathrm{Cu}-\mathrm{K} \alpha$ radiation $(40 \mathrm{kV} / 30 \mathrm{~mA})$ and scanned over a range of 2 thetas, values from 10 to $80^{\circ} \mathrm{C}$ at a scanning rate of $0.05 \% .4 \mathrm{~s}$ $[34,35]$.

\subsection{Studies of in-vitro dissolution.}

In-vitro dissolution tests were performed using the USP paddle method as per Indian pharmacopeia. Dissolution experiments were conducted in $900 \mathrm{~mL}$ of $0.1 \mathrm{~N} \mathrm{HCl}(\mathrm{pH} 1.2), 0.5$ percent sodium lauryl sulfate (SLS), acetate buffer ( $\mathrm{pH} 4.5$ ), and 0.5 percent SLS ( $\mathrm{pH} 7.4$ ) saline phosphate buffer maintained at $37.5 \pm 0.5^{\circ} \mathrm{C}$. The constant stirring of $75 \pm 1 \mathrm{rpm}$ was maintained. $5 \mathrm{ml}$ of samples were taken and filtered using a 0.45 -micron filtrate with an acceptable interval of $(5,10,15,30,45,60,90$, and $120 \mathrm{~min})$, respectively. The samples were analyzed using UV-visible spectrophotometers at $450 \mathrm{~nm} \mathrm{[36]}(\mathrm{n}=3)$. 
2.20. Ex-vivo permeation studies.

Male Wistar rats weighing in between 180 to $200 \mathrm{~g}$ were used in the study. The animals were housed in separate cages and maintained under experimental conditions. The rats were sacrificed with excess ether inhalation method. The abdomen was opened, and a segment of the ileum was removed and flushed Krebs-Ringer solution is used to remove mucus and adhered intestinal contents from the digestive tract. One end of the intestine segment was tied, and the other end was tied. The equivalent dose of optimized formulation of polyherbal liquisolid powder compacts was introduced into the lumen and was tightly closed. The tissues were placed in a $250 \mathrm{ml}$ beaker with continuous aeration and maintained a temperature of 37 ${ }^{\circ} \mathrm{C}$ in a $100 \mathrm{ml}$ of phosphate buffer $(\mathrm{pH}$ 6.8). At predetermined time intervals $(5,10,15,30$, 45,90 , and $120 \mathrm{~min}$ ), an aliquot of $1 \mathrm{ml}$ was collected and replenished with equal volumes of the medium. The samples were treated with an equal volume of methanol, and the supernatant was quantified for polyherbal extract using the HPLC method. Control (pure polyherbal extract) and marketed formulation (Ibuprofen) were also included in the comparative analysis study. The cumulative amount of polyherbal extract permeated (Q) was plotted against time (t). The steady-state flux (Jss) was calculated and represented as per the unit area. The permeability coefficient $(\mathrm{Kp})$ of the polyherbal formulation through the intestine was calculated by dividing steady-state flux with the initial concentration of polyherbal formulation in the donor compartment. The enhancement ratio (ER) was calculated by using the following equation [37]:

$$
\mathrm{ER}=\frac{\text { Jss of liquisolid formulation }}{\text { Jss of control }}
$$

\subsubsection{Stability studies.}

According to the ICH guidelines, stability studies were carried out by keeping the prepared formulations of liquisolid powder compacts at $40{ }^{\circ} \mathrm{C}$ with an $\mathrm{RH}$ of $75 \% \pm 5 \%$ for three months. The samples were withdrawn after 90 days and were analyzed for assay purity, disintegration time, and in-vitro release studies.

\section{Results and Discussion}

\subsection{Preparation of the polyherbal extract.}

The polyherbal extract consists of Hibiscus cannabinus, Murrayakoenigii, and Tabernaemontana divaricata yielded $55.8 \% \mathrm{w} / \mathrm{v}$.

\subsection{Phytochemical screening.}

The phytochemical screening of Polyherbal extract has shown Alkaloids, Saponins, Steroids, Sterols, Flavonoids, Carbohydrates, Proteins, Amino acids, Gums, Mucilage, Tannins, and Phenolic compounds (results are not cited here).

\subsection{Acute oral toxicity studies.}

The acute toxicity tests performed in accordance with OECD 420 guidelines revealed that the polyherbal extract is safe when administered orally to Wistar rats at a dose of $2000 \mathrm{mg} / \mathrm{kg}$ body weight per oral dose. 
3.4. Anti-inflammatory activity (in-vitro screening method).

3.4.1. Protein denaturation method.

The effect of anti-inflammatory activity of the polyherbal extracts (methanolic extract of H. Cannabinus, M. koenigii, and T. divaricata leaves at different doses) are shown in Table 1 and Figure 1.

Table 1. Effect of Poly Herbal Extract (PHE) on proteinase inhibitory activity

\begin{tabular}{|c|c|c|c|c|c|c|}
\hline $\begin{array}{l}\text { S. } \\
\text { No. }\end{array}$ & $\begin{array}{c}\text { Poly herbal } \\
\text { extract } \\
\text { Concentration } \\
(\mu \mathrm{G} / \mathrm{ML})\end{array}$ & 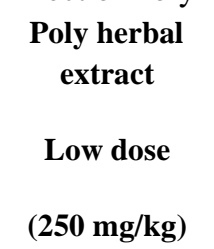 & $\begin{array}{c}\text { Poly herbal } \\
\text { extract } \\
\text { Medium dose } \\
(500 \mathrm{mg} / \mathrm{kg})\end{array}$ & $\begin{array}{l}\text { Poly herbal extract } \\
\text { High dose } \\
(900 \mathrm{mg} / \mathrm{kg})\end{array}$ & $\begin{array}{l}\text { Indomethaci } \\
\text { n }(10 \mathrm{mg} / \mathrm{kg})\end{array}$ & $\begin{array}{c}\text { Control } \\
\text { (absorba } \\
\text { nce } \\
\text { mean } \pm \text { sd) }\end{array}$ \\
\hline 1 & 50 & $37.32 \pm 015 * * *$ & $39.34 \pm 0.46$ & $42.25 \pm 0.87$ & & \multirow{7}{*}{$\begin{array}{c}0.6532 \pm 0 \\
07\end{array}$} \\
\hline 2 & 100 & $44.67 \pm 0.73$ & $47.65 \pm 0.78$ & $49.79 \pm 0.64$ & $87.94 \pm 0.74$ & \\
\hline 3 & 200 & $62.78 \pm 0.69 * * *$ & $65.55 \pm 0.26$ & $68.04 \pm 0.97 * * *$ & $96.84 \pm 0.14$ & \\
\hline 4 & 400 & $72.43 \pm 0.44$ & $69.86 \pm 0.64 * * *$ & $73.40 \pm 0.33$ & & \\
\hline 5 & 600 & $76.71 \pm 0.72$ & $77.57 \pm 0.76$ & $82.37 \pm 0.44$ & & \\
\hline 6 & 800 & $81.24 \pm 0.34$ & $85.94 \pm 1.12 * * *$ & $86.26 \pm 1.13 * * *$ & & \\
\hline & IC 50 & 132.00 & 103.03 & 52.59 & & \\
\hline
\end{tabular}

Each value represents the mean \pm SEM. $\mathrm{n}=6$, group were compared with control $* * * \mathrm{P}<0.001$, considered extremely significant when compared to vehicle-treated group.

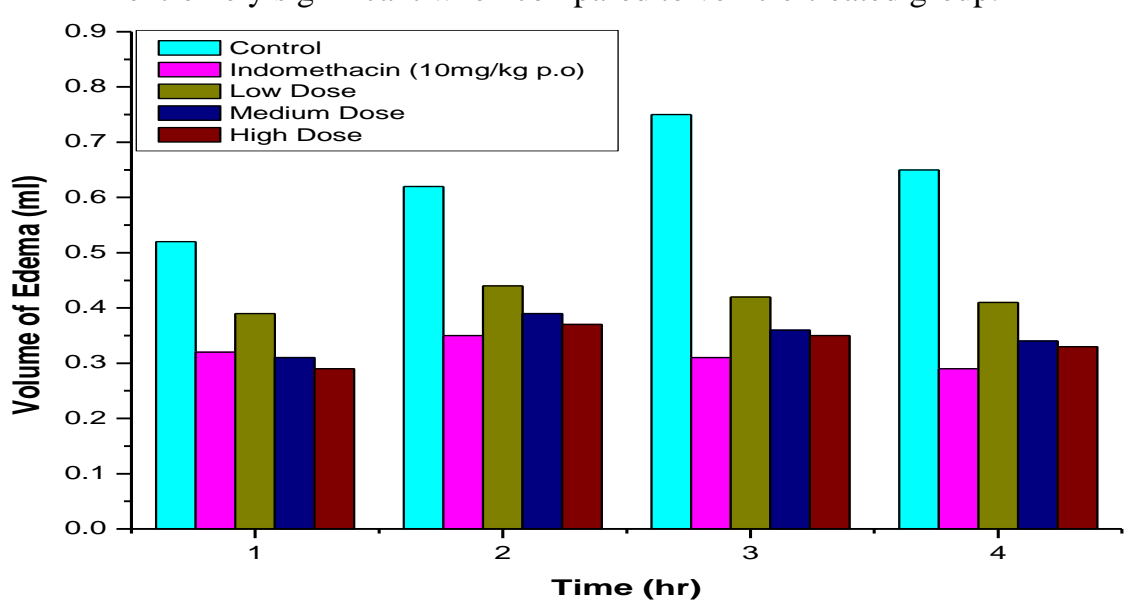

Figure 1. Poly Herbal Extract (PHE) on proteinase inhibitory activity.

\subsubsection{Carrageenan-induced paw edema test.}

At different doses, the polyherbal extract of $\mathrm{H}$. Cannabinus, M. koenigii, and $\mathrm{T}$. divaricata was administered using gum acacia as a carrier in suspension for $18 \mathrm{~h}$ and $2 \mathrm{~h}$ before the induction of edema by carrageenan injection and monitored the edema progression. The maximum paw edema response and the area under the curve (AUC) are reported in total edema response. Indomethacin (standard) and alcoholic (methanolic) extract of $H$. Cannabinus, $M$. koenigii and T. divaricata (low dose- $100 \mathrm{mg} / 50 \mathrm{mg} / \mathrm{kg}$, medium-dose $200 \mathrm{mg} / 100 \mathrm{mg}$ per $\mathrm{kg}$, high dose-400mg/200mg per $\mathrm{kg}$ ) doses showed inhibitory activity. The total paw edema response was calculated as AUC and observed that the inhibition is over $6 \mathrm{~h}$ compared to the control group. The results were tabulated in Table 2 and depicted in Figure 2. 
Table 2. Effect of Poly Herbal Extract (PHE) on Carrageenan-induced rat paw edema.

\begin{tabular}{|c|c|c|c|c|c|}
\hline \multirow{2}{*}{$\begin{array}{c}\text { Time } \\
\text { (hr) }\end{array}$} & \multicolumn{5}{|c|}{ Volume of edema (ml) } \\
\hline & Control & $\begin{array}{c}\text { Indomethacin } \\
\text { (10mg/kg. P.O) }\end{array}$ & $\begin{array}{c}\text { Poly herbal extract } \\
\text { Low dose } \\
(250 \mathrm{mg} / \mathrm{kg}, \text { p.o })\end{array}$ & $\begin{array}{l}\text { Poly herbal extract } \\
\text { Medium dose } \\
(500 \mathrm{mg} / \mathrm{kg}, \text { p.o })\end{array}$ & $\begin{array}{c}\text { Poly herbal extract } \\
\text { High dose } \\
(900 \mathrm{mg} / \mathrm{kg}, \text { p.o })\end{array}$ \\
\hline 1 & $0.52 \pm 0.03$ & & $0.39 \pm 0.04(25 \%)^{*}$ & $0.31 \pm 0.05(40.3 \%)$ & $0.29 \pm 0.04(44.2 \%)$ \\
\hline 2 & $0.62 \pm 0.04$ & $0.35 \pm 0.05(43.5 \%)^{*}$ & $0.44 \pm 0.06(29 \%)$ & $0.39 \pm 0.03(37.0 \%)^{*}$ & $0.37 \pm 0.03(40.3 \%)^{*}$ \\
\hline 3 & $0.75 \pm 0.07$ & $0.31 \pm 0.04(58.6 \%)^{*}$ & $0.42 \pm 0.03(44.0 \%)^{*}$ & $0.36 \pm 0.04(52.0 \%)^{*}$ & $0.35 \pm 0.06(53.3 \%)$ \\
\hline 4 & $0.65 \pm 0.05$ & $0.29 \pm 0.03(58.6 \%)^{*}$ & $0.41 \pm 0.05(58.6 \%)$ & $0.34 \pm 0.06(58.6 \%)$ & $0.33 \pm 0.02(58.6 \%)$ \\
\hline
\end{tabular}

Each value represents the mean \pm SEM. $\mathrm{n}=6$, group were compared with control $* \mathrm{P}<0.05$, considered extremely significant when compared to vehicle-treated group.

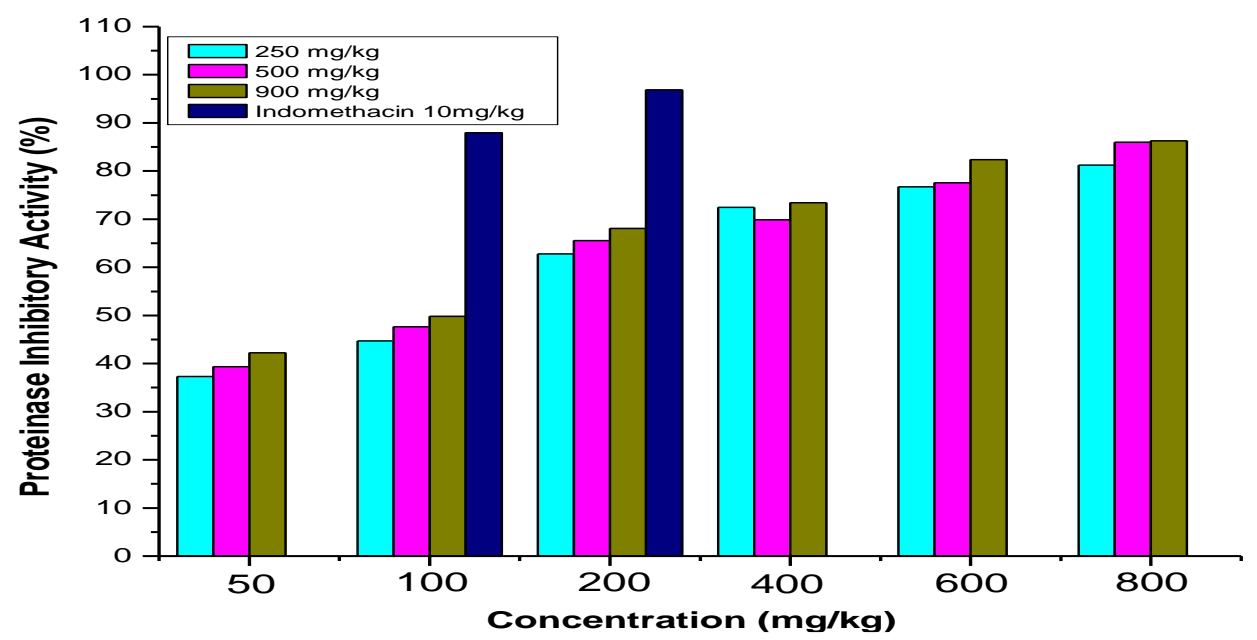

Figure 2. Poly Herbal Extract (PHE) on Carrageenan-induced rat paw edema.

\subsubsection{Cotton pellet granuloma test.}

The effect of anti-inflammatory activity of the polyherbal extract of methanolic extract of $H$. Cannabinus, M. koenigii, and T. divaricata leaves at different doses was conducted. The results were shown in Table 3 and Figure 3.

Table 3. Effect of Poly Herbal Extract (PHE) on cotton pellet granuloma in rats.

\begin{tabular}{l|l} 
Treatment & Dry weight of granuloma \\
\hline Control $(\mathrm{CMC} 0.5 \% 10 \mathrm{ml} / \mathrm{kg})$ & $45.80 \pm 1.74$ \\
Indomethacin $(5 \mathrm{mg} / \mathrm{kg})$ & $19.77 \pm 1.76(56.8 \%)^{*}$ \\
PHE-Low dose $(250 \mathrm{mg} / \mathrm{kg})$ & $33.23 \pm 2.61(27.44 \%)^{*}$ \\
PHE-Medium $(500 \mathrm{mg} / \mathrm{kg})$ & $29.77 \pm 1.28(35.0 \%)$ \\
PHE-High dose $(900 \mathrm{mg} / \mathrm{kg})$ & $23.84 \pm 1.87(47.94 \%)$ \\
\hline
\end{tabular}

Difference between the weight of dissected dry cotton pellet and weight of cotton pellet before implantation. Values are expressed as mean \pm SEM, $n=6$ in each group. Values in parentheses indicate percent inhibition of granuloma formation. $* \mathrm{P}<0.01$ as compared with control.

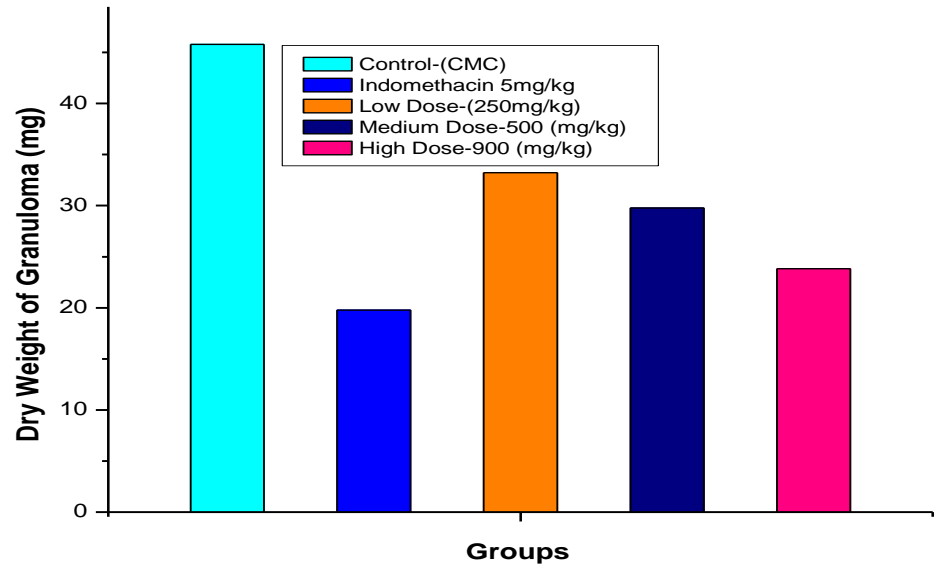

Figure 3. Poly Herbal Extract (PHE) on cotton pellet granuloma in rats. 


\subsection{Pre-formulation studies.}

3.5.1. Solubility studies.

The solubility studies of Polyherbal Formulation (PHF) showed that the liquisolid compacts were very poorly soluble in water (i.e., $0.14 \mathrm{mg} / \mathrm{ml}$ ) to increase the solubility was enhanced by the addition of propylene glycol up to $6.5 \mathrm{mg} / \mathrm{ml}$. The use of span 20 and 80 also enhanced the solubility of liquisolid compact to 0.44 and $3.46 \mathrm{mg} / \mathrm{ml}$, respectively. It is evident from the results that propylene glycol was the best solvent for the formulations. The results were shown in Table 4.

Table 4. Solubility of Poly Herbal Extract (PHE) with various solvents.

\begin{tabular}{l|l|l} 
S.No. & Solvent & Solubility $(\mathbf{m g} / \mathbf{m l})$ \\
\hline 1 & Propylene glycol & $5.48 \pm 0.02$ \\
\hline 2 & Span 80 & $3.51 \pm 0.04$ \\
\hline 3 & Span 20 & $0.81 \pm 0.03$ \\
\hline 4 & Water & $0.71 \pm 0.01$ \\
\hline 5 & Methanol & $7.48 \pm 0.07$ \\
\hline 6 & Hydro-alcohol & $4.57 \pm 0.08$
\end{tabular}

3.5.2. Pre-formulation studies of polyherbal extract.

The free flow properties of the polyherbal extract were determined and tabulated in Table 5. The tapped Density ( $\sigma \mathrm{t}$ ), bulk Density $(\sigma \mathrm{b})$, Hausner's ratio, Carr's index, and Angle of repose $(\theta)$ were studied, respectively. The range of bulk and tapped density was found to be $0.511 \pm 0.001$ to $0.573 \pm 0.014 \mathrm{~g} / \mathrm{cm} 3,0.596 \pm 0.02$ to $0.656 \pm 0.05 \mathrm{~g} / \mathrm{cm} 3$ respectively. The range of Carr's index and Hausner's ratio was found to be $11.10 \pm 0.10$ to $15.95 \pm 0.061 \%$, $1.123 \pm 0.02$ to $1.194 \pm 0.01 \%$, respectively. The Angle of repose will be high for the cohesive powder, and the lower in non-cohesive powders, Angle of repose of polyherbal extract of Liquisolid compacts was in the range of $25.64 \pm 0.65$ to $27.36 \pm 0.14 \theta$, which proved to be good free flow properties of the polyherbal extract. All the micromeritic properties of blended powder samples were in the standard limits and had good compressibility.

Table 5. Micromeritic properties of prepared pre-compression Poly Herbal Extract (PHE) liquid-solid powders.

\begin{tabular}{|c|c|c|c|c|c|c|}
\hline S. No & Formulation & $\begin{array}{c}\text { Tapped } \\
\text { density } \\
\left(\mathrm{gm} / \mathbf{c m}^{3}\right)\end{array}$ & $\begin{array}{l}\text { Bulk density } \\
\left(\mathrm{gm} / \mathrm{cm}^{3}\right)\end{array}$ & $\begin{array}{l}\text { Hausner's } \\
\text { Ratio }\end{array}$ & $\begin{array}{c}\text { Carr's index } \\
(\%)\end{array}$ & $\begin{array}{l}\text { Angle of } \\
\text { repose }(\theta)\end{array}$ \\
\hline 1 & F1 & $0.601 \pm 0.07$ & $0.541 \pm 0.020$ & $1.113 \pm 0.07$ & $11.10 \pm 0.10$ & $26.31 \pm 0.49$ \\
\hline 2 & $\mathrm{~F} 2$ & $0.656 \pm 0.05$ & $0.573 \pm 0.014$ & $1.152 \pm 0.05$ & $13.91 \pm 0.15$ & $25.64 \pm 0.65$ \\
\hline 3 & F3 & $0.599 \pm 0.25$ & $0.511 \pm 0.001$ & $1.123 \pm 0.02$ & $11.39 \pm 0.03$ & $25.79 \pm 0.40$ \\
\hline 4 & $\mathrm{~F} 4$ & $0.627 \pm 0.09$ & $0.526 \pm 0.024$ & $1.126 \pm 0.09$ & $12.07 \pm 0.11$ & $27.36 \pm 0.14$ \\
\hline 5 & F5 & $0.655 \pm 0.07$ & $0.522 \pm 0.029$ & $1.154 \pm 0.03$ & $14.24 \pm 0.22$ & $26.61 \pm 0.08$ \\
\hline 6 & F6 & $0.596 \pm 0.02$ & $0.563 \pm 0.051$ & $1.194 \pm 0.01$ & $15.95 \pm 0.061$ & $25.68 \pm 0.14$ \\
\hline
\end{tabular}

3.6. Formulation of polyherbal extract with liquisolid compacts.

The required amount of polyherbal formulation (100 mg) was weighed and transferred to a mortar and pestle. The resultant mixture was dispersed in different non-volatile liquids (Transcutol HP, propylene glycol, Tween 80, and Tween 20, Methanol, Hydro alcohol) to get $100 \% \mathrm{w} / \mathrm{w}$ concentration. Following research findings in the literature, it has been discovered that using a 100 percent excipient ratio will result in tablets with sufficient hardness and better dissolution profiles. Because of this, the excipient ratio $(\mathrm{R})$ was maintained at its constant value of 100. To avoid excessive trituration and particle size reduction, it was necessary to add only 
the calculated amount of carrier and coating material to the dispersion media before blending it in a porcelain dish [21]. To the dispersion media, about $40 \mathrm{mg}$ of croscarmellose sodium was added and mixed thoroughly. The final mixture was compressed into tablets using a multistation rotary punching machine (Rimek Minipress I, Karnavati Engineering Pvt. Ltd., and Gujarat, India). The compression force was adjusted depending upon the weight of the individual tablet and ingredients in the formulation. Formulations were prepared individually using forty tablets in a batch (Table 6).

Table 6. Formulation of Polyherbal Formulation (PHF) liquid-solid compacts.

\begin{tabular}{l|l|l|l|l|l|l} 
S.No & Formulation & Vehicle & $\begin{array}{l}\text { Load } \\
\text { factor } \\
(\mathbf{L f})\end{array}$ & $\begin{array}{l}\text { Avicel } \\
\mathbf{P H 1 0 2} \\
(\mathbf{m g})\end{array}$ & $\begin{array}{l}\text { Aerosil } \\
\mathbf{2 0 0}(\mathbf{m g})\end{array}$ & $\begin{array}{l}\text { Weight of } \\
\text { tablet } \\
(\mathbf{m g})\end{array}$ \\
\hline 1 & F1 & Tanscutol Hp & 0.247 & 50 & 15 & 205 \\
\hline 2 & F2 & Propylene Glycol & 0.224 & 100 & 20 & 260 \\
\hline 3 & F3 & Tween 80 & 0.139 & 150 & 30 & 320 \\
\hline 4 & F4 & Tween 20 & 0.158 & 200 & 40 & 380 \\
\hline 5 & F5 & Methanol & 0.107 & 250 & 50 & 440 \\
\hline 6 & F6 & Hydroalcohol & 0.101 & 300 & 60 & 500
\end{tabular}

\subsection{Post compression studies of the polyherbal formulation (PHF).}

It was determined the effects of various evaluation parameters such as hardness, flow properties, friability, and disintegration time, and the results were recorded (Table 7). In order for any dosage form to function properly, it must maintain a constant drug dosage between each unit in a given batch. F1-F4 formulations were complied with the content uniformity as per Indian pharmacopeia in the range of $98.43 \%, 99.02 \%, 88.28 \%$, and $94.89 \%$, respectively. Formulations F5 and F6 showed $83.25 \%$ and $81.63 \%$ content uniformity which does not comply with Indian pharmacopeia limits. This may be due to the insufficient quantity of the liquid to disperse the amount of drug taken, which failed to dissolve the drug with carrier and coating material during the mixing process. A satisfactory friability with less than one percent loss was observed in all of the liquisolid compact tablets (F1-F6), and none of the tablets showed signs of cracking, splitting, or broken pieces.

According to Indian pharmacopoeia, all of the formulations had weight variations within the standard limits (less than 5 percent) and passed the evaluation test. Formulations F2, F3, F4 and F6 showed acceptable hardness $\left(3-4 \mathrm{~kg} / \mathrm{cm}^{2}\right)$ whereas F1 and F5 showed hardness $<2 \mathrm{~kg} / \mathrm{cm}^{2}$. Formulation F2 disintegrated within $13 \mathrm{~min}$. Other formulations took around 2231 minutes to disintegrate completely longer than the disintegration time. The more likely it is that the drug will be released from the dosage form later. As a result, those individuals were excluded from further research. F2 was selected as the optimal formulation based on its flow properties, hardness, and disintegration time formulation, and further characterization studies were carried out on it.

\subsection{Physicochemical characterization.}

\subsubsection{Fourier Transform Infrared Spectroscopy (FTIR).}

FTIR studies were conducted to understand the physicochemical properties of substances concerning drug compatibility. FTIR spectra of polyherbal extract, Aerosil 200, Avicel PH102, and physical mixture of drug, carrier/coat material, and optimized formulation (F2) were studied, and their interpretations were depicted in Figure 4. Polyherbal extract's 
infrared spectrum exhibits distinct peaks at $3446 \mathrm{~cm}^{-1}$ (non-aromatic $\mathrm{C}-\mathrm{H}$ stretch), $3063 \mathrm{~cm}^{-1}$ (aromatic C-H stretch), $2957 \mathrm{~cm}^{-1}$ (aliphatic C-H stretch), $1697 \mathrm{~cm}^{-1}$ (carbonyl group), and $1599 \mathrm{~cm}^{-1}$ (aromatic $\mathrm{C}=\mathrm{C}$ bend and stretch), with a peak at $1458 \mathrm{~cm}^{-1}$ indicating the presence of a $\mathrm{C}=\mathrm{C}$ aromatic group. In both the physical mixture and the liquisolid formulation, the appearance of all of these peaks and the absence of any new peaks indicates that there is no chemical interaction between the drug and excipients.

\subsubsection{Differential scanning calorimetry.}

The DSC thermogram of polyherbal formulation showed sharp endothermic peaks with an onset of $266.45^{\circ} \mathrm{C}$ and peak temperature $268.74^{\circ} \mathrm{C}$, correspondings to its melting point. The presence of the same peak in the final formulation indicates no interaction between drug and excipients during the formulation preparation. The decreases in the enthalpy $(\Delta \mathrm{H})$ suggested that the reduction in crystallinity or partial amorphization is due to the drug and was confirmed by XRD studies.

\subsubsection{X-ray powder diffraction analysis.}

The XRD studies on the product or formulation were performed. The crystallinity form changes can have an enormous impact on the bioavailability of the molecule due to the changes in solubility and dissolution. The XRD patterns of the polyherbal extract showed sharp, distinct peaks notably at $2 \theta$ diffraction angles of $6^{\circ}, 14^{\circ}, 15^{\circ}$, and $22^{\circ}$, indicating that the polyherbal extract was in in the state of crystallinity. The appearance of peaks at the same diffraction angles in the XRD of the physical mixture indicated no change in the crystalline structure. Similarly, the decrease in intensity of the peaks at the same diffraction angles in optimized formulation showed that the polyherbal extract may have undergone the solid-state transition from crystalline to amorphous.

\subsection{In vitro dissolution studies.}

The solubility decreased as the $\mathrm{pH}$ of the solution rise. As a result, buffers with higher $\mathrm{pH}$ values (acetate buffer $\mathrm{pH} 4.5$ and phosphate buffer $\mathrm{pH}$ 7.4) were chosen for the dissolution studies, which serve as discriminating media in the experiment. It was necessary to conduct dissolution studies in respective media using SLS at 0.5 percent weighted average concentrations in order to maintain the conditions under study. The cumulative percent drug release of the drug, marketed product, and optimized formulation (F2) in $0.1 \mathrm{~N} \mathrm{HCl}, \mathrm{ABS}$, and PBS with $0.5 \%$ SLS at different time intervals were studied (Figure 4). The dissolution profile showed complete drug release within 30 min for polyherbal formulation compared to $46.3 \%$ from marketed tablets and $71.82 \%$ from the plain drug. The reduced dissolution rate of the marketed product may be due to its slow disintegration in the dissolution media. In ABS with $0.5 \%$, SLS complete drug release was observed within 15 min with formulation F2, whereas < $60 \%$ of the drug was released from plain drug and marketed tablet. The optimized polyherbal formulation F2 showed complete drug release in $30 \mathrm{~min}$ compared to $82.90 \%$ from the marketed tablet and $65.62 \%$ of drug release from the plain drug in phosphate buffer containing $0.5 \%$ SLS. The results correlated that the polyherbal formulation has low solubility at higher $\mathrm{pH}$. 


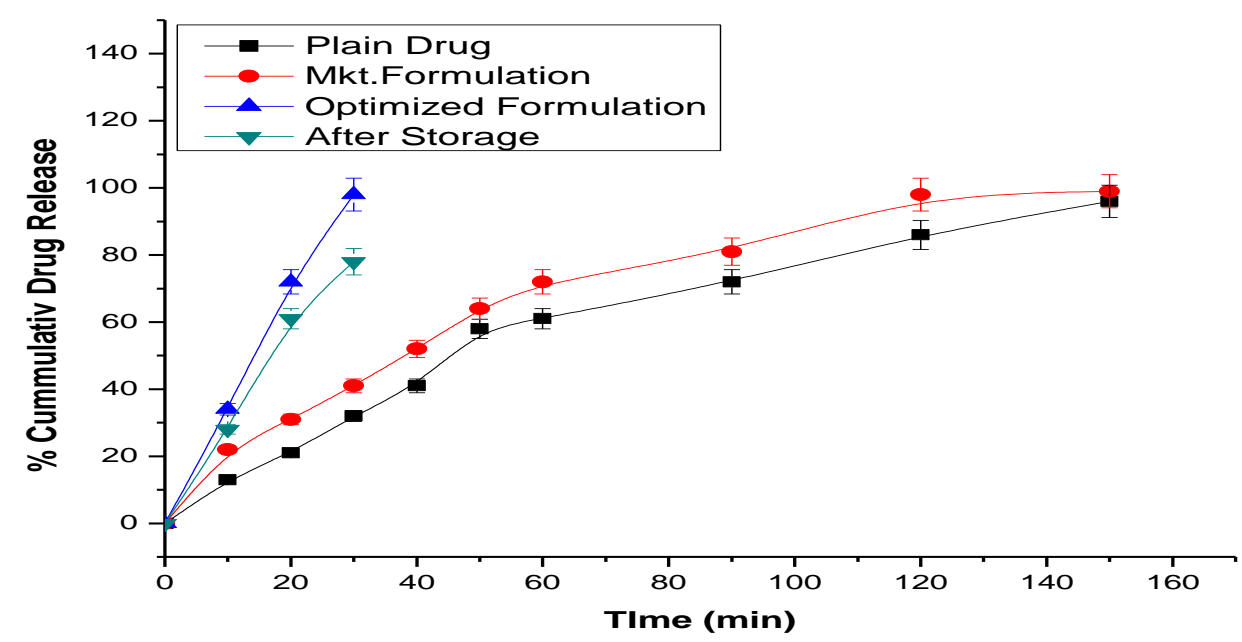

Figure 4. In vitro dissolution studies on different formulations.

\subsection{Ex-vivo intestinal permeation study.}

The rate and extent of absorption depend not only on dissolution and rather than permeation across the gastrointestinal tract but also on their limiting factors for absorption. Therefore, to gain insight into the ability of liquisolid compact tablet formulations for improved absorption, ex-vivo permeation studies were carried out using Wistar rat intestinal segment. Since most drugs will get absorbed in vivo from the small intestine, rat tissue was more relevant. We have used the ileum portion to assess the potentiality of liquisolid compacts to improve polyherbal formulation's permeation. Ex-vivo permeation studies did not show any significant $(p \geq 0.05)$ difference between marketed formulation and polyherbal extract. The amount of cumulative drug permeated across the intestine was calculated and represented in Figure 5. The results showed that the control to marketed formulation was $524 \pm 24$ and $398 \pm 4 \mu \mathrm{g}$, respectively and was significantly increased to $1592 \pm 8 \mu \mathrm{g}$ with optimized formulation $(\mathrm{P} \leq$ 0.05) (Table 8). The flux was also increased considerably with F2 optimized formulation compared to that of control and marketed tablet $(\mathrm{P} \leq 0.05)$. The enhancement ratio of more than $1(3.80 \pm 0.1)$ for optimized F2 indicated an enhanced permeation compared to the prepared polyherbal extract formulation.

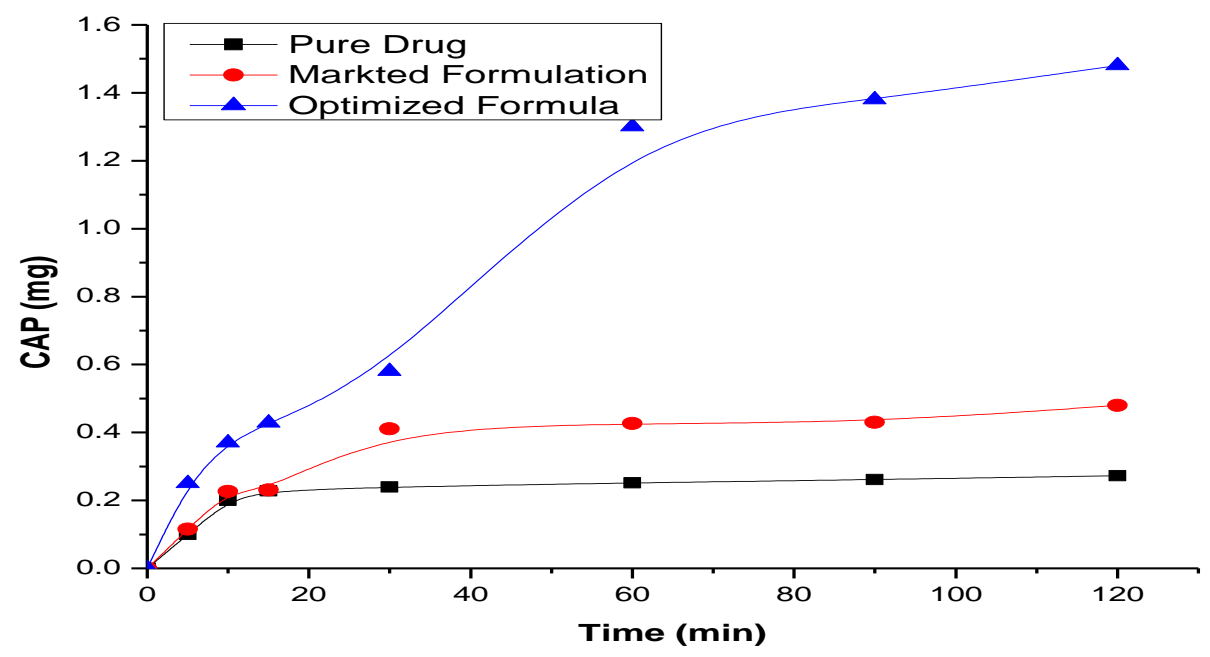

Figure 5. Ex-vivo Permeation studies of PHF. 


\begin{tabular}{l|l|l|l|l}
\multicolumn{5}{c}{ Table 8. Ex-vivo intestinal permeation study of PHF formulation across rat intestine. } \\
S.No & Formulation & $\mathbf{J s s}\left(\mu \mathrm{g} / \mathbf{c m}^{\mathbf{4}} / \mathbf{h}\right)$ & $\mathbf{K p}(\mathbf{c m} / \mathbf{h}) \mathbf{x ~ 1 0} \mathbf{1 0}^{-7}$ & ER \\
& & & & \\
\hline 1 & Pure PHF & $0.3015 \pm 0.224$ & $0.1507 \pm 0.0541$ & - \\
\hline 2 & F2 formulation & $0.8936 \pm 0.059$ & $0.4468 \pm 0.0246$ & $4.4 \pm 0.3$ \\
\hline 3 & Market formulation & $0.3259 \pm 0.016$ & $0.1629 \pm 0.0023$ & $1.62 \pm 0.004$
\end{tabular}

\subsection{Stability studies.}

The stability analysis on the optimized liquisolid compact was done for three months at $40{ }^{\circ} \mathrm{C} / 75 \% \pm 5 \% \mathrm{RH}$. Samples were studied for their stability after 3 months and found that they are stable ( $>>0.05)$. The similarity factor $(F 2)$ for the optimized formula was 67.80 (Table 9), which showed that the release rate of dissolution before and after the stability analysis is very stable.

\section{Conclusions}

The studies were conducted on optimized formulations and polyherbal extract of liquisolid compact powder to assess and improvise poorly soluble drugs' solubility. During the process, the conversion of a crystalline molecule to its amorphous state will reduce the particle size by micronizing, grinding, inclusion complexation, solid dispersions, self-emulsifying drug delivery system, nano-suspends, and adsorption of drugs to hydrophilic aerogels.

The Liquisolid Powder Compacts are one of the most promising strategies for increasing the release rate. Spireas are liquisolid systems that consist of a non-volatile, watermiscible liquid vehicle, stable pharmaceutical particles, and selected excipients. The porous carrier material is integrated into the liquid component, a liquid, a drug suspension, or a drug solution in appropriate fluid-free automobiles. A liquid film is formed on the particle's surface when filled and was adsorbed immediately by the fine particles.

This results in a clear dry, free flow, and compressible liquisolid compact powder. In addition to improving the release of drug products, the liquisolid method is a promising technique due to its ease of manufacturing, low production cost, and the possibility of industrial production because of the strong free flow and compaction properties of the liquisolid formulations. The quantitative approach to the formulation of liquisolid systems to quantify the number of powder excipients needed was very well studied and developed by Spireas.

The suitable free-flowing, compressible liquisolid compact powder can only be obtained if the maximum liquid load called the liquid load factor (Lf) is not exceeding 3.7. The formulations, stability, and anti-inflammatory activity are tested using both in-vitro \& ex-vivo trials were studied.

The polyherbal liquisolid compact powder formulation F5 has a minimum hardness of $1 \mathrm{~kg} / \mathrm{cm}^{2}$, while the hardness of F2 and F6 was $41 \mathrm{~kg} / \mathrm{cm}^{2}$. A given ideal liquisolid compact powders should be evaluated for parameters such as friability, hardness, decay, dissolution rate, and differential scanning calorimetry, and X-ray powder diffraction analysis. The formulations' anti-inflammatory action was tested using the paw edema system and cotton pellet method in both methods.

The polyherbal extract of liquisolid compact powder formulation was formulated and evaluated concerning pre-evaluations and post-formulation parameters. The anti-inflammatory activity of the polyherbal extracts showed promising activity. The study suggested that a 
promising strategy for improving the dissolution rate of poorly soluble poly-herbal extracts. This may be due to the developed formulation's Liquisolid compact nature and improved weather resistance by making propylene glycol suspension. Liquisolid compact powder could be made with a polymer, i.e., MCC PH 102 and the coating agent AEROSIL ${ }^{\circledR} 200$. The FTIR studies showed that the drug is more compatible with excipients studied. In DSC and XRD studies, the crystallinity of polyherbal extracts has decreased in liquisolid compact formulation. Thus, we propose that the developed liquisolid compact powder formulation can be used as an alternative strategy for treating inflammatory disorders.

\section{Funding}

This research did not receive any specific grant from funding agencies in the public, commercial, or not-for-profit sectors.

\section{Acknowledgments}

The authors would like to thank Hetero Drugs. Pvt Ltd. Hyderabad for their enormous support and providing the Drugs and Chemicals. Vinod Kumar Yata would like to thank the Department of Biotechnology, Government of India, for providing financial support from "DBT-RA Program in Biotechnology \& Life Sciences".

\section{Compliance with ethical standards}

All institutional and national guidelines for the care and use of laboratory animals were followed.

\section{Conflicts of interest}

I hereby confirm that all authors have approved the manuscript for submission. We declare that we have no conflicts of interest.

\section{References}

1. Bao, T. D.; Li, Y. J.; Weng, X. G.; Yang, Q.; Zhang, Y. F.; Dong, Y. Studies on pharmacokinetics of evodiamine and rutaecarpine in rats plasma after oral administration extracts of Euodiae Fructus. China $J$. Chin Mater Med. 2011, 36, 3519-3522, https://doi.org/10.4268/cjcmm20112429.

2. Cai, Q.; Wei, J.; Zhao, W.; Shi, S.; Zhang, Y.; Wei, R. Toxicity of Evodiae fructus on rat liver mitochondria: the role of oxidative stress and mitochondrial permeability transition. Molecules 2014, 19, 21168-21182, https://doi.org/10.3390/molecules191221168.

3. Cai, H.; Xu, Y.; Xie, L.; Duan, Y.; Zhou, J.; Liu, J. Investigation on spectrum-effect correlation between constituents absorbed into blood and bioactivities of Baizhu Shaoyao San before and after processing on ulcerative colitis rats by UHPLC/Q-TOF-MS/MS coupled with gray correlation analysis. Molecules 2019, 24, 940-965, https://doi.org/10.3390/molecules24050940.

4. Chen, J.; Gao, Y.; Tan, P.; Wang, L.; Zhang, X. L.; Zhang, Y. F. Analysis on volatile oil constituents in euodiae fructus and processed products by GC-MS. Chin. J. Inf. TCM 2016, 23, 91-95, https://doi.org/10.3969/j.issn.1005-5304.2016.12.022.

5. Gavaraskar, K.; Dhulap, S.; Hirwani, R. R. Therapeutic and cosmetic applications of Evodiamine and its derivatives-A patent review. Fitoterapia 2015, 106, 22-35, https://doi.org/10.1016/j.fitote.2015.07.019.

6. Ji, S.; He, D. D.; Su, Z. Y.; Du, Y.; Wang, Y. J.; Gao, S. K. P450 enzymes-based metabolic interactions between monarch drugs and the other constituent herbs: a strategy to explore compatibility mechanism of Sangju-Yin. Phytomedicine, 2019, 58, 152866, https://doi.org/10.1016/j.phymed.2019.152866. 
7. Tamaki, Y.; Jinjo, K.; Uechi, S.; Hongo, F.; Sameshima, K.; Yoga, S.; Mokuzai, Gakkaishi. Cholesterollowering effect of water-soluble polysaccharides from kenaf (H. cannabinus) seeds in rats. FacAgric University Ryukyusa Okinawa Japan 2015, 47:159-163.

8. Lee, YG.; Byeon, SE.; Kim, JY.; Lee, JY.; Rhee, MH.; Hong, S.; Wu, JC.; Lee, HS.; Kim, MJ.; Cho, DH.; Cho, JY. Immunomodulatory effect of Hibiscus Cannabinus extracts on macrophage functions. J Ethnopharmacol 2020; 113: 62-71, https://doi.org/10.1016/j.jep.2007.04.019.

9. Díaz, O.; Ferreiro, T.; Rodríguez-Otero, J.; Cobos, Á. Characterization of Chickpea (Cicer arietinum L.) Flour Films: Effects of $\mathrm{pH}$ and Plasticizer Concentration, International Journal of Molecular Sciences 2019, 20, 1246, https://doi.org/10.3390/ijms20051246.

10. Jiang, H.; Yang, L.; Xing, X.; Yan, M.; Guo, X.; Yang, B. Chemometrics coupled with UPLC-MS/MS for simultaneous analysis of markers in the raw and processed Fructus Xanthii, and application to optimization of processing method by BBD design. Phytomedicine, 2019, 57, 191-202, https://doi.org/10.1016/j.phymed.2018.12.020.

11. Jin, X.; Zhang, Z.; Sun, E.; Li, S.; Jia, X. Statistically designed enzymatic hydrolysis of an icariin $/ \beta$ cyclodextrin inclusion complex optimised for production of icariin. Acta Pharma Sin B 2012, 2: 83-89, https://doi.org/10.1016/j.apsb.2011.12.004.

12. Li, W.; Sun, L.; Chen, X. M.; Liu, C.; Song, Y.; Ding, H.; X. X. Analysis of Evodia rutaecarpa hepatotoxic part and absorbed components in rat serum based on UPLC-TOF-MS. J. Chin. Mass. Spectro. Soc 2017, 38, 282-293, https://doi.org/10.7538/zpxb.youxian.2016.0065.

13. Joshi, P.; Yadaw, G.S.; Joshi, S.; Semwal, R.B.; Semwal, D.K.. Antioxidant and anti-inflammatory activities of selected medicinal herbs and their polyherbal formulation. South African Journal of Botany, 2020, 130, 440-447, https://doi.org/10.1016/j.sajb.2020.01.031.

14. Deldar, Y.; Pilehvar-Soltanahmadi, Y.; Dadashpour, M.; Montazer Saheb, S. Rahmati-Yamchi, M.; Zarghami, N. An in vitro examination of the antioxidant, cytoprotective and anti-inflammatory properties of chrysin-loaded nanofibrous mats for potential wound healing applications, Artif. Cells Nanomed. Biotechnol 2018, https://doi.org/10.1080/21691401.2017.1337022.

15. OECD Guidelines 423. OECD guideline for testing of chemicals. Acute Oral Toxicity- Acute Toxic Class Method 2001.

16. Jargalsaikhan, B.; Ganbaatar, N.; Urtnasan, M.; Uranbileg, N.; Begzsuren, D. Anti-Inflammatory effect of Polyherbal formulation on Carrageenan and Lipopolysaccharide-induced acute inflammation in Rats, Biomed Pharmacol J 2019, 12, https://dx.doi.org/10.13005/bpj/1811.

17. Nuzzo, D.; Amato, A.; Picone, P.; Terzo, S.; Galizzi, G.; Bonina, FP.; Mulè, F.; Carlo, MD. A natural dietary supplement with a combination of nutrients prevents neurodegeneration induced by a high fat diet in mice. Nutrients, 2018, 10, E1130, 1-18, https://dx.doi.org/10.3390/nu10091130.

18. Ramshetti, Prasad.; Jadi, Kumar.; Bakshi,Vasudha.; AK, Chettupalli. Formulation development and evaluation of allopurinol solid dispersions by solvent evaporation technique. Int. J. Appl. Pharm 2018, 10, 168-171, https://doi.org/10.22159/ijap.2018v10i4.25311.

19. Ijaz, M.; Ali, I.; Hussain, A. Diabetes mellitus in Pakistan: the past, present, and future, Int Jou of Dia in Deve Coun 2019, 1-2, https://doi.org/10.1007/s13410-019-00754-x.

20. Chukwuma, C. I.; Matsabisa, M. G.; Ibrahim, M. A.; Erukainure, O. L.; Chabalala, M. H.; Islam, M. S.; Medicinal plants with concomitant anti-diabetic and anti-hypertensive effects as potential sources of dual acting therapies against diabetes and hypertension: a review, Jour of Ethnopharmacology 2019, 235, 329360, https://doi.org/10.1016/j.jep.2019.02.024.

21. Qureshi, M. N.; Numonov, S.; Aisa, H. A. Total polyphenolic compounds, total flavonoids, GC-MS analysis of volatile constituents, evaluation of antioxidant and antimicrobial activities of Prunus dulcis nuts, Pak J of Phar Sci 2019, 32, 4, 1461-1466. PMID: 31608863.

22. Clark, J..; Taylor, C.; Zahradka, P. Rebelling against the (insulin) resistance: a review of the proposed insulinsensitizing actions of soybeans, chickpeas, and their bioactive compounds, Nutrients 2018, 10, 4, 434, https://doi.org/10.3390/nu10040434.

23. Sami, DG.; Heiba, HH.; Abdellatif, A. Wound healing models: A systematic review of animal and non-animal models. Wound Med, 2019, 24, 8-17, https://doi.org/10.1016/j.wndm.2018.12.001.

24. Palomer, X.; Pizarro-Delgado, J.; Barroso, E.; Vázquez-Carrera, M. Palmitic and oleic acid: the yin and yang of fatty acids in type 2 diabetes mellitus, Trends in Endocrinology \& Metabolism, 2019, 29 178-190, https://doi.org/10.1016/j.tem.2017.11.009. 
25. Ishnava, K. B. In - vitro study on $\alpha$ - amylase inhibitory activity of selected ethnobotanical plant extracts and its herbal formulations, Int J Pharmacogn Chinese Med, 2019, 2, 1-11.

26. Kharwade, RS.; Mahajan, NM. Formulation and Evaluation of Nanostructured Lipid Carriers Based AntiInflammatory Gel for Topical Drug Delivery System. Asian J Pharm Clin Res. 2019, 12, 286-291, https://doi.org/10.22159/ajpcr.2019.v12i4.32000.

27. Díaz, T.; Ferreiro, J.; Rodríguez-Otero, Cobos, Á. Characterization of Chickpea (Cicer arietinum L.) Flour Films: Effects of pH and Plasticizer Concentration, International Journal of Molecular Sciences, 2019, 20, 1246, https://doi.org/10.3390/ijms20051246.

28. Kabashima, K.; Honda, T.; Ginhour, F.; Egawa, G. The immunological anatomy of the skin. Nat Rev Immunol 2019, 19, 19-30, https://doi.org/10.1038/s41577-018-0084-5.

29. Krishna, S.; Sravanthi, P.; Abdul, Mohd.; Prakash, Diwan. Improved oral delivery of clonazepam through liquisolid powder compact formulations: In-vitro and ex-vivo characterisation. Powder Technology 2014, 256, 336-344, https://doi.org/10.1016/j.powtec.2014.02.026.

30. Ajinkya, Mate.; Padmashri, Ade.; Ajay, Pise.; Sachin, More.; Shilpa, Pise.; Rohini, Kharwade. Formulation and Evaluation of Polyherbal Gel for the Management of Acne, Int J Cur Res Rev, 2021, 13, 117-122, http://dx.doi.org/10.31782/IJCRR.2021.13432.

31. Bhinge, SD.; Bhutkar, MA.; Randive, DS.; Wadkar, GH.; Kamble, SY.; Kalel, PD. Formulation and evaluation of polyherbal gel containing extracts of Azadirachta indica, adhatoda vasica, piper betle, Ocimum tenuiflorum and Pongamia pinnata. Marmara Pharm J, 2019, 23, 44-54.

32. Gangane, PS.; Ghughuskar, SH.; Mahapatra, DK.; Mahajan, NM. Evaluating the role of Celosia argentea powder and fenugreek seed mucilage as natural super-disintegrating agents in gliclazide fast disintegrating tablets. Int J Curr Res Rev 2020, 12, 101- 108.

33. Paul, S., Modak, D., Chattaraj, S. et al. Aloe vera gel homogenate shows anti-inflammatory activity through lysosomal membrane stabilization and downregulation of TNF- $\alpha$ and Cox-2 gene expressions in inflammatory arthritic animals. Futur J Pharm Sci, 2021, 7, 12, https://doi.org/10.1186/s43094-020-001636.

34. Shedoeva, A.; Leavesley, D.; Upton, Z.; Fan, C. Wound healing and the use of medicinal plants 2019, eCAM 2684108:1-30.

35. Saleem, A.; Saleem, M.; Akhtar, MF.; Shahzad, M.; Jahan, S. Moringa rivae leaf extract attenuate Complete Freund's adjuvant induced arthritis in Wistar rats via modulation of inflammatory and oxidative stress biomarkers. Inflammopharmacol 2020, 28, 139-151, https://doi.org/10.1007/s10787-019-00596-3.

36. Parasakthi, N.; Deepika, R.; Sivanathan, C.; Abubackkar Sithiq, PD.; Venkateshan, N. Invivo Activity of Polyherbal Gels Prepared Using Carbopol. International Journal of Novel Trends in Pharmaceutical Sciences 2020, 10, 63-66, https://doi.org/10.26452/ijntps.v10i3.1354.

37. MP, V.; Purushotham, KG. Screening of Phytochemical Analysis and In vitro Bioactive of Polyherbal Formulation. Pharmacognosy Journal 2020, 12:1525-1533, https://doi.org/10.5530/pj.2020.12.209. 